\title{
Awards and Prizes
}

\section{Ronald Breslow and Murray Moo-Young Win American Chemical Society Awards}

Professors Ronald Breslow and Murray Moo-Young, both active IUPAC Members, have won prestigious awards from the American Chemical Society this year.

Prof. Breslow, Chemistry and University Professor at Columbia University in New York City and Titular Member of IUPAC's Organic Chemistry Division (III) Committee as well as Member of the Subcommittee on Bioorganic Chemistry, was honored with the Priestley Medal, the highest ACS award, during the society's national meeting last spring in Anaheim, CA, USA. Previously the winner of awards too numerous to cite here, Breslow is noted for his pioneering research in nonbenzenoid aromatic chemistry; enzyme-catalyzed reactions; biomimetic approaches to synthesis of enzymes and complex carbohydrates; and synthesis of simple anticancer compounds consisting of two solventlike molecules linked together with a carbon chain. Prof. Breslow says he continues to "like to make new molecules that we think will have interesting properties".

Prof. Moo-Young, Professor of Chemical Engineering at the University of Waterloo, Ontario, Canada and a National Representative for IUPAC's Commission on Biotechnology, was presented with the Marvin J. Johnson Award in Microbial and Biochemical Technology at the spring ACS national meeting. Prof. MooYoung has been at the forefront of establishing quantitative correlations for mass transfer, mixing, and kinetics in bioreactor systems. He is also noted for the development of process biotechnologies that employ fragile cell cultures in the production of drugs, biopolymers, and foodstuffs. His recent research has focused on elucidating bioremediation enhancement. In that work, he has used physicochemical pretreatment strategies to control and abate environmental pollution.

\section{Researchers Benefit from Chemical Structure Association Trust Awards and Bursaries}

We thank Dr. Wendy A. Warr (Wendy A. Warr \& Associates, 6 Berwick Court, Holmes Chapel, Cheshire CW4 7HZ, England, UK; Tel./Fax: +44 1477 533837; E-mail: wendy@warr.com; Web site: http://www.warr.com), Chairman of the IUPAC Committee on Printed and Electronic Publications (CPEP), for arranging for the preparation of the following article by Dr. William G. Town (billt@chemweb.com), Chairman of the Chemical Structure Association Trust.

\section{Origin of the Chemical Structure Association (CSA) Trust}

The Chemical Structure Association (CSA) Trust was founded in response to two related problems: universities having trouble funding research, and industry having difficulty recruiting suitably trained personnel. It is a registered charity that aims to promote research and development in the field of storage, processing, and retrieval of information about chemical structures, reactions, and compounds. It was established in 1998 with money from the Chemical Structure Association (although the Trust is a legally separate entity).

Research in the field of chemical structure handling has shown considerable success in recent years, and results have been rapidly reflected in practice. Both similarity and 3D structure searching have been well established for some time, even though much of the research behind them was only carried out in the 1980s. There is still a pressing need for such research in the chemical information arena. Combinatorial chemistry and molecular diversity are just two examples of exciting, ground-breaking fields. The CSA Trust exists to support such development, particularly research, attendance at conferences, etc., which might otherwise have been impossible because of lack of funds.

\section{Annual Awards, Awardees, and Areas of Research}

Since its inception, the Trust has supported a very broad range of research by scientists from tremendously diverse backgrounds and geographical locations. The annual awards and bursaries have by no means been limited to the United States and Western Europe; a number of Russian projects have been assisted, for instance. Award winners have ranged from an American undergraduate who has been engaged in a year's research at Moscow State University, to a Chinese predoctoral student working at the University of North Carolina, to a researcher from the National Chemical Laboratory in Pune, India. Specific areas of research have included quantitative structure-activity relationships (QSAR) and combinatorial chemistry, chemical literature data extraction, computer-assisted synthesis, genetic algorithms, neural networks, reaction databases, and quantum chemistry.

A CSA Trust Annual Award is USD 3 200/GBP 2 000, which the winner can put toward attending a relevant conference, toward travel (to collaborate with another research group, for instance), or toward hardware or software to assist with a research project. The award is not usually given for hardware and software alone, how- 